16

\title{
Culture and Ethics in First Nations Educational Research
}

Josiah Taylor, Evie Plaice, \& Imelda Perley

University of New Brunswick

In this paper, we share phenomena experienced by a multi-cultural research team working collaboratively with Wolastoq (Maliseet) First Nations Elders to document rapidly disappearing Wolastoq language, culture, and knowledge. This knowledge will ultimately be stored in databanks for future educational, community, and heritage use. Embedded within this research experience is a constantly evolving ebb and flow of culture, being, and relationships. As a collaborative research team, we explore ethical ramifications of dynamic, symbiotic relationships we share with Elder participants, requirements of university ethical review processes, and how this process shapes the knowledge that we collaboratively produce. We question how this nexus of cultures and ethics of researchers and collaborators directs the educational materials that we construct. Situated between the high tide of ethical standards and the low tide of the application of these ethics, is where the tides meet, and standards and praxis interact. Lastly, we suggest ways to supplement the ethics review process for social and educational research to better respect the individual rights and rationality of participants with whom we research, deepening the significance of such studies and promoting social justice.

\section{Considering Culture and Ethics in First Nations Educational Research}

$T^{n}$ the following essay we explore how ethical demands are mediated and interpreted within the context of a collaborative research team composed of university-based academics and members from the local Wolastoq nation. The primary ques- tions we applied to our research were drawn from the Ownership, Control, Access, and Possession (OCAP) Report of the National Aboriginal Health Organization (2007). They are:

1 . Who owns the research?

2. Who controls the research process?

3. Who is involved in implementing the research? 
4. Who benefits from the research and, in this case, the ethics review process?

\section{Introduction to the Research}

\section{Before the Dam: Documenting Spoken Wolastoq in} Educational, Spiritual and Cultural Context is funded by the Social Sciences and Humanities Research Council Strategic Grants, and is based at the University of New Brunswick. The goal of this project is to work with Wolastoq Elders ${ }^{1}$ to create an audio/ video archive of recordings to preserve Wolastoq language, knowledge, and culture. Historically, Wolastoq territory spans a large area of Maine (USA), New Brunswick, and Quebec (Canada), being centered in what is known in English as the Saint John River valley. Wolastoqewiyik means the ancestral people of the beautiful and bountiful river (Perley, 2007/8).

The purpose of our research is to work with consenting Wolastoq Elders to document Wolastoq language using film and audio recordings. Embedded in the language is cultural and historical knowledge, which has been taught primarily through oral education. Within a context of Euro-Canadian cultural, educational, linguistic, and political domination for centuries, Wolastoq language and culture has been severely diminished and destroyed through the imposition of assimilationist policies, with the intentions of absorbing Wolastoq nations into Canadian culture. According to David Crystal's (2000) scale of language loss, Wolastoq language is currently "seriously endangered" if not "moribund," with very little significant usage in communities or institutions.

Our project members have been working with Wolastoq Elders on language, knowledge, and culture over many years. Many Elders have come to be friends, teachers, and inspiring mentors. At least partially as a result of the significance of these relationships, we have increasingly focused on cultivating respect for Elders involved in the research process as participants, colleagues, and carriers of knowledge. Moreover, we acknowledge that Elders are founda- tional to our research and, through this research, to our place in the academic world. Through questioning experiences of researchers and participants, we aim to open fertile ground for debate and thought in how we conduct research and how we may be able to do so in a manner that is more aware, respectful, and socially just. To accomplish this we will concentrate primarily on question four (although all the questions are linked): Who benefits from the research, and the ethics review process? Sub-questions to this are: how can we improve research experiences for participants? How can we practice the greatest respect for those whose knowledge on which our research depends?

\section{Questioning University Ethical Protocols}

It took several months for Before the Dam to get through an ethics review at the University of New Brunswick (UNB) Research Ethics Board (REB), and in this paper we consider the context, significance, and rigor of this process and the discourses upon which the process relies. While these perspectives in which the REB is embedded are taken as universal, they are local to the context of the academy and its Euro-Canadian roots (Jardine, 2005). The UNB REB process follows The Tri-Council Policy Statement: Ethical Conduct for Research Involving Humans (1998), which includes the Social Sciences and Humanities Research Council, the primary financial supporter of our research. Universities are institutions with origins in, and a long history of, Eurocentrism. Who are the actual people who review and have the agency to authorize (or not) what is allowed as research? "They have privileged the scientific method as a means to access the truth...in fact, one only has to review the Board of Consulting Editors of any journal in the field to ascertain who is charged with saying what counts as true" (Gallagher, 2007). We need only look at the composition of many REBs to see that they are largely dominated by those who are in the privileged position to conduct research rather

\footnotetext{
${ }^{1}$ Locally, Elders are considered as such by peers and community members for a set of factors, such as, but not limited to, special lived experience, community involvement, applied wisdom, leadership, responsibility, and fulfilling traditional roles.
} 
than those being researched. The claim to authority over ethics and truth follows from this specific positioning. This imbalance is something that needs to be addressed at the institutional level, since it is not necessarily within the scope of individual REB members who bring to the REB process their time and good intentions. Section 3.5 of the University Policy on Research involving Humans (2009) states that:

REB Membership shall have at least the following membership (total membership being at least five):

- one member knowledgeable in ethics;

- one member knowledgeable in relevant law;

- two members from faculties normally conducting research involving humans;

- one community representative (two if the total membership exceeds five).

While it is clear that the University REB process is attempting to be inclusive, we question whether these attempts have gone far enough. As it currently stands, the UNB policy does not adequately allow for, and does not sufficiently specify, the need to have cultural diversity, nor indigenous peoples as members of the REB. The Tri-Council Policy Statement (1998) expands on the last point: "The community member requirement...is essential to help broaden the perspective and the value base of the REB beyond the institution, and thus advances dialogue with, and accountability to, local communities." This statement does not specify that the community representative must be from within the cultural group involved in the study. While it is entirely possible that a Wolastoq person reviewed our research proposal, it was not mandatory.

Given the history of Wolastoq First Nations people in the local area, and that UNB operates on land once occupied entirely by Wolastoq people, there is certainly right for at least one Wolastoq person to review research proposed to be done in historically Wolastoq territory. Moreover, in this case, not just doing research in Wolastoq territory, but with Wolastoq people, there is not simply a right for Wolastoq people to be represented on the REB, but a responsibility.
Section 2.2 (Principles) of the University Policy on Research Involving Humans (2009) proclaims "research involving humans is to be carried out with respect for human dignity, for free and informed consent, for vulnerable persons, for privacy and confidentiality, for justice and inclusiveness, and for the need to balance harms and benefits." While the language used emphasizes respect and justice, it is unclear how this is actually implemented. The REB protocols as listed above need to be critically tried and tested in the practice of research, each context raising new questions about how such requirements are to be improved and implemented.

For Before the Dam research we asked participants for written consent to be involved in the research, before interviews commenced, and for consent to use their materials once the interviews were completed. While interviewing was underway, this also frequently involved seeking specific permission to use a participant's media in any publications surrounding the ongoing research. While this consent process is essential from the contemporary academic/ institutional point of view, in practice it is often the case that participants are at least partially unclear about what the consent process entails, and for what purpose it exists. In many cases, ours included, the various levels of consent required us to seek approval from community and governance structures within the Aboriginal community as well as from individual participants. The desires and expectations of people involved at each level were frequently different and sometimes even contradictory. These complexities of access and permission are exacerbated by the implicit assumption embedded in the REB process that Aboriginal communities are homogenous, and that the various political levels that govern Aboriginal communities share the same desires for their peoples and communities. The marked difference in understanding around the REB process between participants, academics, and administrators begs the question: Who is the consent process for? Our experience inclines us to think that the consent process does not go beyond a safeguarding of academics and sponsoring institutions from potential future liability. The intellectual property and privacy rights of participants are not equally protected, or respected. With this in mind, 
it appears that we need to supplement the ethics review process to be more concerned with respecting individual participant's rights.

\section{Compensation}

The world in which academics now engage in order to achieve success in funding is one that is little understood beyond academia. The Elders with whom we work have little understanding of the relatively high level of funding on which university-based researchers operate. It is clear that, with questions such as: "what do you do for work?" there is an understanding that visiting is a matter of us coming to listen for the pleasure and edification of learning from their wisdom. The work of research is not understood, certainly not as something that has a monetary value, and this realization causes some awareness of inequality that only certain members of the research equation are compensated. When research is regularly supported with thousands of dollars in funding, is it fair, just, or respectful to give Elders token (yet sincere) gifts, like tobacco, tea, beans, or fish, and occasionally also small honoraria when often they do not have enough money for absolute essentials such as energy bills in the bitter cold of winter? Thus far, Elder knowledge and time is only beginning to be recognized or remunerated through major funding agencies such as SSHRC. New funding strategies are beginning to recognize the value of such input by allowing for honoraria to be paid to key Elders (AREI, 2008). This change in itself is monumental. However, for the work and knowledge involved on the part of the participant, honoraria are minor financial appreciations.

With this understanding, however, it is clear that the REB process is not deeply enough concerned with equality or justice, or undoing neo-colonial discourses and knowledge/power structures. Through the REB, the University has a vested interest in allowing research to be done, and therefore in passing proposals through the ethics review, as it brings increased funding, prestige, and notoriety to the University.

One must ask if it is just or respectful to request that participant collaborators give to the researchers with little financially reciprocated. The relationship is not entirely one-sided, as the Elders with whom we work also have expectations from the research, such as having books or films made with their teachings. In our research we are working to benefit the communities with our databank (an invaluable resource). However, while we (and many) researchers operate on a significant grant, there is not adequate consideration for financially compensating our participant collaborators. Elders provide their wisdom and their time to our project for little remuneration. We academics are paid for the knowledge that we accumulate and employ, whereas the researched - our colleagues, the Elders - are not. Elders do not often have their knowledge legitimized by academic degrees, denying them recognition within the academic world. This denies value to their knowledge and expertise, knowledge for which we are working to bolster appreciation. It is an important and significant task to begin to accredit Elder knowledge.

Larger discourses and improvements in research can be revealed through reviewing some of the forces at play in our experiences and relationships as academics, graduate students, researchers, and collaborators. While personal to us, many of the points discussed are also found within contexts of institutional discourses and therefore are endemic to academic research and knowledge production. Through academics and colonialism, these are long reinforced relationships, in which the academy has focused on marginalized people, maintaining and perpetuating their marginality. Another aspect of this marginalization is that studying other communities can turn them into objects of knowledge, perpetuating unjust knowledge/ power structures (Mills, 2003). While we institutionally privileged ones are obviously receiving much benefit from this research, it is not simply uni-directional. Assuming in the end the materials do make it back to the individual participants, their families and communities, along with future generations will benefit from these multi-media records of their ancestors and traditional knowledge.

Respecting participants' rationality and intelligence, how can we supplement ethical reviews to heighten concern with participants' 
perspectives on their experience, improving the research process for non-academic participants?

First we must recognize that social research takes place in the complex world of humans, living within inevitable power relations and imbalances. Our research necessitates that we work with and depend on human participants. As part of respecting human rights, we must respect that research participants are themselves rational beings, more than solely objects of research. Satterthwaite asks: "what... happen[s], in midst of all this, to the ownership of knowledge? Whose knowledge counts?" (Satterthwaite, Atkinson, \& Gale, 2003). On one level, participants' knowledge is valued to the point that we want them to be part of our study - but not enough that participants are justly compensated. While our primary research goal is to actively collect knowledge and information on culture, language, and traditions, perhaps we could also ask questions and collect information on how the participants feel about their part in the research process.

As a regular part of research, as academics, we meet regularly and discuss thoughts and concerns regarding the project. However, we rarely ask participants for their own critiques of the study. By initiating such a survey, we could better respect participants' intelligence, improve our relationships, deepen the significance of the work, and improve how we do social research in the future. An outline of possible questions for discussion is offered here:

- Have you felt that your knowledge and experiences (culture/traditions) have been honoured?

- What do you think are the strengths of the research experience?

- How could we improve the interview process? What could we do differently?

- Have you felt comfortable throughout the interview(s)? Is there anything we could do to increase your comfort?

- What do you think is fair compensation for your involvement/work?

- Would you be involved again in a similar study? Why or why not?
- Are there any other topics or stories you would like to talk about?

- What would you like done with the recorded stories, language, and knowledge?

By directly asking collaborator participants such questions we can begin to better understand research experiences from participants' perspectives. While this participant-based ethical/experiential review process is not currently a requirement for social scientific and educational research, as academics we could integrate this sort of survey into all our human based research. As The Tri-Council Policy Statement (1998) makes explicit in Section 6 (Research Involving Aboriginal Peoples): "The agencies have not held sufficient discussions with representatives of the affected peoples or groups, or with the various organizations or researchers involved. The agencies have therefore decided that it is not yet appropriate to establish policies in this area." Perhaps we will further open up discussion regarding aboriginal participants rights and experiences, and help participants better know the research process, and their role(s) in it. This could even raise interest and appreciation in the research process from communities in which we work, and help to grow a new generation of researchers.

\section{Conclusion}

While current ethical review processes are an essential part of human-based social and educational research, we argue that they do not sufficiently include nonacademic participants' reflections and perspectives on the research process. Without sincere and deep concern for the participants, we may be reproducing social inequalities, which we strive to diminish. We plan to improve our research through combining required University ethical review processes with our own surveys of participants' experiences.

"At every moment, step by step, one must confront what one is thinking and saying with what one is doing, with what one is."

Foucault in Jardine, 2005 


\section{References}

Aboriginal Research Ethics Initiative [AREI] of the Interagency Advisory Panel on Research Ethics. (2008). Issues and options for revisions to the tri-council policy statement on ethical conduct of research involving humans (TCPS): Section 6: Research involving Aboriginal peoples. Retrieved from http://www.ger.ethique.gc.ca/ policy-politique/initiatives/docs/AREI__February_2008_-_EN.pdf

Canadian Institutes of Health Research, Natural Sciences and Engineering Research Council of Canada, Social Sciences and Humanities Research Council of Canada. (1998). The tri-council policy statement: Ethical conduct for research involving humans. Retrieved from http://www.pre.ethics.gc.ca/eng/policy-politique/tcps-eptc/

Crystal, D. (2000). Language death. Cambridge: Cambridge University Press.

Gallagher, S. (2007). Educational psychology: Disrupting the dominant discourse. New York: Peter Lang.

Jardine, G.M. (2005). Foucault and education. New York: Peter Lang.

Mills, S. (2003). Michel Foucault. London, UK: Routledge Taylor and Francis Group.

First Nations Centre. (2007). OCAP: Ownership, Control, Access, and Possession. Sanctioned by the First Nations Information Governance Committee, Assembly of First Nations. Ottawa: National Aboriginal Health Organization. Retrieved from http://www.naho.ca/firstnations/ english/documents/FNC-OCAP_001.pdf

Perley, I. (2007/8). Wabanaki worldview class. University of New Brunswick, Fredericton, NB, Canada.
Satterthwaite, J., Atkinson, E., \& Gale, K. (Eds.). (2003). Discourse, power and resistance: Challenging the rhetoric of contemporary education. Stoke on Trent, UK: Trentham Books.

University of New Brunswick. (2009). University policy on research involving humans. Retrieved from: http:/www.unb.ca/research/ors/forms/ UniversityPolicy_RIH_27Feb09.pdf

\section{Biographies}

Josiah Taylor is a Master's student in the Faculty of Education at the University of New Brunswick, concentrating on respectfully using media to document cultural and environmental knowledge. His research has been supported by a Social Sciences and Humanities Research Council Joseph-Armand Bombardier Canada Graduate Scholarship.

Evie Plaice is an Associate Professor in the Faculty of Education and Department of Anthropology at the University of New Brunswick, and focuses on land usage and restitution.

Imelda Perley is a Doctoral student in the Faculty of Education at the University of New Brunswick, a keeper of sacred ceremonies, and a Wolastoq language warrior. 